\title{
Benjamin e a questão da experiência
}

\author{
Cidiane Lobato
}

\section{RESUMO}

Walter Benjamin é um filósofo contemporâneo que constrói uma conciliação entre "verdade" e "beleza", indissociáveis na experiência que torna possível o conhecimento ontológico. A busca da verdade não admite uma primazia da "razão" sobre o "sensível", do "universal" sobre o "singular", do "conceito" sobre a "ideia" e do "ser" sobre a "história", mas, ao contrário, se constitui a partir de uma dialética entre os opostos que emergem da experiência do singular presente na história. Este trabalho se propõe a uma breve apresentação da questão da experiência em Walter Benjamin. Para o alcance deste objetivo, escolhemos por abordagem: (I) traçar um breve resumo dos principais pontos da Crítica da Razão Pura, de Kant, que versam, dentre outras questões filosóficas, sobre as condições de possibilidade do conhecimento e da experiência; (II) mostrar como as condições de possibilidade do conhecimento propostas por Kant conduziram a um reducionismo das condições de possibilidade de fazer experiência; (III) demonstrar a ampliação do significado de "experiência" por Benjamin em oposição à definição de "experiência" elaborada por Kant; e, finalmente, (IV) apontar as consequências do pensamento de Benjamin para a Filosofia a partir do significado por ele proposto do que seja "experiência".

Palavras-chave: História. Crise da Razão. Experiência. Mito. Ideia.

\section{RÉSUMÉ}

Walter Benjamin est un philosophe contemporain qui concilie « vérité » et «beauté », les deux indissociables dans l'expérience permettant la connaissance ontologique. La quête de la vérité n'admet pas la primauté de la «raison » sur le « sensible », de « l'universel » sur le « singulier », du « concept » sur « l'idée » et de « l'être » sur « l'histoire »; elle se constitue, au contraire, à partir d'une dialectique entre les opposés qui émergent de l'expérience du singulier présent dans l'histoire. Ce travail propose de faire une brève présentation de la question de l'expérience chez Walter Benjamin. À cette fin, nous avons choisi: (I) de tracer un bref résumé des principaux points de la Critique de la raison pure, de Kant, concernant, entre autres questions philosophiques, les conditions de possibilité de la connaissance et de l'expérience; (II) de montrer comment les conditions de possibilité de la connaissance proposées par Kant ont conduit à un réductionnisme des conditions de possibilité de faire expérience; (III) de démontrer l'élargissement du sens de « l'expérience » par Benjamin en opposition à sa définition donnée par Kant; et (IV), finalement, d'indiquer les conséquences de la pensée de Benjamin pour la Philosophie à partir du sens qu'il donne, lui, à ce que soit «l'expérience ».

Mots-clés: Histoire. Crise de la raison. Expérience. Mythe. Idée. 
Na Crítica da Razão Pura (CRP), Kant apresenta o que ele elabora como sendo as "condições de possibilidade do conhecimento". Sua proposição central é a de que para conhecê-los, os objetos são regulados pelas formas transcendentais do sujeito. Tal proposição foi apresentada por Kant como a "revolução copernicana" na Filosofia e pode ser mais bem entendida quando contextualizada frente aos "problemas do conhecimento" levantados por empiristas anteriores a Kant, como David Hume. Em sua sinopse do Tratado da Natureza Humana, Hume afirmara que "quase todo raciocínio se reduz à experiência; e a crença que acompanha a experiência se explica somente como um sentimento peculiar, ou seja, como uma concepção vívida produzida pelo hábito" (grifo nosso); ou seja, segundo Hume, o conhecimento seria o resultado do processo de associação das representações singulares de um sujeito e, sendo assim, os juízos proferidos por este sujeito seriam necessariamente dependentes de suas experiências particulares.

Em contraposição a Hume, Kant afirmou na CRP as condições de possibilidade do conhecimento de modo que nele fosse possível verificar absoluta independência de toda e qualquer experiência particular de um sujeito. Não só isso, mas argumentou que, para que fosse possível realizar a verificação da verdade do conhecimento, seria necessário também delimitar as "possibilidades do sujeito em conhecer". E foi assim que Kant justificou as condições de possibilidade de conhecimento dos objetos pelo sujeito através da existência do que ele chamou de "juízos sintéticos a priori", isto é, juízos de verdade enunciados a partir de conceitos a priori no sujeito transcendental. Em outras palavras, ao contrário de Hume, Kant afirmou que, sob condições bem delimitadas, ou mais especificamente, apenas no espaço dos fenômenos ou daquilo que pode ser conhecido pelo sujeito transcendental, haveria uma possibilidade de o conhecimento não ser considerado como necessariamente dependente da experiência particular de um sujeito - a de que um juízo de verdade se dá através de conceitos a priori, necessários e universais, presentes na razão humana.

Necessidade e universalidade foram então os critérios aplicados por Kant para a verificação da verdade do conhecimento: "necessidade", porque um juízo verdadeiro só poderia ser pensado como sendo necessário; "universalidade", porque um juízo necessário não admitiria qualquer exceção à regra que propõe. Sabemos que as características de necessidade e universalidade do conhecimento são derivadas dos 
chamados "princípios da razão" - identidade, não contradição, terceiro excluído e razão suficiente -, que subjazem toda a história do pensamento ocidental. Pensadores antigos, como Platão e Aristóteles, modernos, como Descartes, Leibniz e Spinoza, iluministas, como Kant e Hegel, cientistas modernos, como Galileu e Newton, além de cientistas contemporâneos reconhecidos mundialmente, como Einstein, assumiram não só a universalidade e necessidade dos "princípios da razão", mas também a necessidade e universalidade dos juízos derivados da aplicação de tais princípios para a elaboração de modelos, leis, regras e teorias (Koyrè, 1991; Hall, 1981). É fácil verificar que a Ciência continua a assumir a necessidade e a universalidade como "premissas científicas" a cada vez que elabora um juízo, assume a verdade que um juízo quer expressar, ou mesmo, quando apenas pretende validar ou negar a verdade de um juízo proferido por alguém.

Não haveria nada de extraordinário nas "premissas científicas", se os "princípios da razão" e suas características de "necessidade" e "universalidade" não tivessem sido aplicadas por Kant para a validação da verdade do conhecimento humano produzido também em lugares de conhecimento não científicos, como a Estética Crítica da Faculdade do Juízo - e a Moral - Crítica da Razão Prática ${ }^{1}$. De fato, importantes pensadores a partir de Friedrich Nietzsche, particularmente Hannah Arendt, interpretaram acontecimentos desastrosos ocorridos nos séculos XIX e XX como resultado direto da aceitação generalizada das "condições de possibilidade do sujeito transcendental" de Kant nos mais diversos campos da atuação humana; os efeitos produzidos por esta aceitação generalizada na contemporaneidade foram também chamados por alguns como "a crise da razão" (Novaes, 1996; Japiassu, 1986) e, neste mesmo sentido, a pós-modernidade foi classificada como sendo nada mais do que "a crise da modernidade" (Vega \& Nascimento, 1999; Harvey, 1996; Touraine, 1994; Giddens, 1991). Entretanto, muito mais do que corroborar ou refutar as condições de possibilidade do conhecimento desenvolvidas por Kant (válidas ainda para muitos cientistas, mesmo após a "Teoria da Incerteza" e a "Mecânica Quântica" de Heisenberg e Bohr), para outros pensadores, tornar-se-ia decisivo para o curso da história da contemporaneidade apontar um outro resultado mais grave ocorrido a partir dos resultados do lluminismo, a saber, o de que assumir as condições de possibilidade do conhecimento, tais como em Kant, necessariamente

\footnotetext{
${ }^{1}$ Para uma rápida introdução à obra de Kant, cf. a resenha (não crítica) Sobre a fundamentação da moral na obra de Kant (Lobato, 2011), disponível em: http://pt.scribd.com/invest_filosofica.
} 
conduzem a um reducionismo nas condições de possibilidade da experiência nos mais diversos campos, como Artes, Filosofia, Política e Religiões.

De um modo mais simples, podemos resumir o problema anterior da seguinte forma: desde Kant, muitos aplicaram a "universalidade" e a "necessidade" dos "princípios da razão" e, portanto, de princípios próprios da "experiência científica" também como "critérios de validação da verdade" de experiências comumente classificadas como "experiências do senso comum", em particular as que se dão no campo das Artes e das Religiões. Dentre os autores que desenvolveram este tema, Walter Benjamin - ensaísta, crítico literário, tradutor, filósofo e sociólogo judeu alemão do século XX - afirmou que o conhecimento produzido pela Filosofia, Artes e Religiões é inerentemente diferente daquele produzido pela Ciência e, por isso mesmo, as "condições de possibilidade do conhecimento" elaboradas por Kant não poderiam ser consideradas adequadas para a "verificação da verdade" do conhecimento produzido em outros campos de experiência não científicos. Para Benjamin, a verdade não é derivada apenas de conceitos abstraídos pela razão e expressos através do logos (palavra grega para se referir à "linguagem racional" ou "conceitual"), mas também produzida a partir de uma interpretação objetiva ${ }^{2}$ (método filosófico apresentado na obra Origem do drama barroco alemão) das ideias produzidas em lugares onde o mythos (palavra grega para se referir à "linguagem narrativa" ou "mitológica") tem valor fundamental, como nas Religiões, nas Artes e, mesmo, na Filosofia. Neste caso, a Filosofia se distinguiria das Religiões e das Artes pelo seu processo particular de construção de ideias e não pela possibilidade de corroborar ou refutar o conhecimento, como defendeu Kant.

Mais ainda, a verdade produzida pela Filosofia é de natureza diversa daquela produzida pela Ciência e o pensamento de Benjamin a respeito pode ser traduzido no seguinte: enquanto a Ciência é o lugar de conhecimento da construção de conceitos, a Filosofia é o lugar de conhecimento da construção de ideias. Neste texto, não procuraremos esgotar o itinerário do filósofo até a proposição anterior; para o objetivo deste trabalho, basta-nos saber que a contraposição entre conceitos e ideias remete ao velho impasse da metafísica ${ }^{3}$, a saber, o dilema entre realismo e idealismo, de antigos e modernos. Realismo e idealismo são extremos equivocados

\footnotetext{
${ }^{2}$ Uma interpretação objetiva é necessária se assumimos que tudo fala em sua própria linguagem.

${ }^{3}$ Metafísica: do grego, ta meta ta physica: aqueles [ta]; após, depois [meta]; aqueles da física [ta physica], que, na Filosofia, diz respeito ao conhecimento do ser ou das coisas tais como são em si mesmas, real e verdadeiramente.
} 
e superá-los equivale à resolução do problema Heráclito-Parmênides ${ }^{4}$. Neste sentido, Benjamin procura superar tanto a metafísica antiga (conhecimento da realidade "em si" ou "independente de nós"; para Platão, tal conhecimento se encontrava nas ideias e para Aristóteles se encontrava nos conceitos) quanto a delimitação da metafísica por Kant (conhecimento da realidade como aquilo que é "para nós", restrita ao "fenômeno", sendo o "em si" ou nôumeno incognoscível; para Kant, o conhecimento se dá a partir dos conceitos a priori no sujeito transcendental).

Mais especificamente, com a afirmação de que a Filosofia é o lugar da construção de ideias, Benjamin quis, em última instância, dissociar da Filosofia a identidade epistemológica que Ihe foi legada a partir de Kant. Sob a perspectiva benjaminiana, uma das principais consequências para a Filosofia, a partir da Crítica da Razão Pura, foi a sua condução de uma indesejável servidão à Teologia a uma necessidade de subordinação à Ciência ${ }^{5}$, pois, das palavras do próprio Kant, fora necessário conduzir a Filosofia ao "caminho seguro da ciência", da lógica, da matemática, a fim de se obter "melhores resultados", como nestas ciências (CRP B XIV-XV). E é exatamente por esta "necessidade de segurança" que passou a imperar na Filosofia aquilo que Benjamin irá chamar de "o empobrecimento da experiência", não só na Filosofia, mas também nas Artes, na Política e nas Religiões. A experiência, diz Benjamin, passou a ser tratada a partir dos parâmetros utilizados na "experiência científica" e os "processos de validação do conhecimento científico" foram aplicados aos juízos proferidos nos mais diversos campos da experiência humana quando, sabemos, Artes, Religiões, Política e Filosofia, além de não produzirem conceitos pelo processo de abstração ${ }^{7}$, também não se desenvolvem somente a partir dos "princípios da razão", tão próprios da Ciência...

\footnotetext{
${ }^{4}$ Os intérpretes atuais consideram que não há extremos entre as filosofias de Heráclito e Parmênides; teria sido a interpretação de Platão a respeito da filosofia de Parmênides a levantar a questão sobre os extremos, os quais foram "resolvidos" através da proposição da "unidade na pluralidade" para a fundação do pensamento metafísico. As obras mais tardias de Martin Heidegger (1889-1976) - A doutrina de Platão sobre a verdade (1942), A caminho da linguagem (1959) e O fim da filosofia e a tarefa do pensamento (1964) - são comumente citadas para a compreensão deste tema.

${ }^{5}$ A Filosofia se "confundia" com a Teologia no período da "Filosofia Cristã" - patrística e medieval - e a "Filosofia Moderna" é interpretada como o rompimento da Filosofia com o mito da Religião Cristã.

${ }^{6}$ Cf. "Experiência e Pobreza" (Benjamin, 1987), edição disponível em

http://bibliotecasocialvirtual.files.wordpress.com/2010/06/walter-benjamin-experiencia-e-pobreza.pdf.

7 Em lugar de "processos de abstração", o filósofo Ludwig Wittgenstein (1889-1951) - considerado por intérpretes como o maior epistemólogo do século XX - propõe "processos de semelhança de família" (Investigações Filosóficas), fazendo eco ao que fora proposto por David Hume no século XVIII.
} 
Walter Benjamin, em toda a sua obra, procurou fazer renascer uma noção mais abrangente do que seja "experiência": desde um texto de sua juventude intitulado "Experiência” (em A Criança, o brinquedo, a educação), mais tarde, em um ensaio sobre a experiência em Kant (Sobre o Programa da Filosofia a vir), em diversos textos dos anos 30, como Experiência e Pobreza, nos trabalhos sobre Baudelaire, e nas teses de 1940, Walter Benjamin exigiu a ampliação do significado de experiência. Procuremos então apresentar os principais pontos de ampliação deste significado na obra de Benjamin em contraposição à definição de experiência proposta por Kant. Começamos por citar a CRP B XVII, cujo trecho será utilizado para toda a comparação entre Benjamin e Kant que faremos a seguir: "(...) a própria experiência é uma forma de conhecimento que exige concurso do entendimento, cuja regra devo pressupor em mim antes de me serem dados os objetos, por consequência, a priori, e essa regra é expressa em conceitos a priori, pelos quais têm de se regular necessariamente todos os objetos da experiência e com os quais devem concordar. (...) só conhecemos a priori das coisas o que nós mesmos nelas pomos”. Desta citação, primeiramente, já explicamos acima: enquanto, para Kant, o conhecimento e a experiência verdadeiros são elaborados a partir de conceitos a priori no sujeito transcendental, para Benjamin, a verdade produzida pela experiência em outros campos que não a Ciência não pode ser traduzida em conceitos porque, menos ainda, é resultado de processos de abstração.

Em segundo lugar, contra a "revolução copernicana" aplicada à metafísica por Kant (CRP B XVI), isto é, a proposição de que, em lugar de a metafísica iniciar seu trabalho investigando o objeto do conhecimento para depois se referir ao sujeito deva começar indagando sobre a possibilidade do sujeito em conhecer os objetos e, posteriormente, afirmar esta possibilidade através da existência de um sujeito transcendental, Benjamin recebe como legado as primeiras descobertas da Filosofia da História do século XIX (posteriormente, ele próprio proporia um novo conceito de história nas teses intituladas Sobre o Conceito de História), posteriores a Kant e já presentes em Hegel, a partir das quais não haveria possibilidade de se afirmar a universalidade do sujeito transcendental, em todos os tempos e lugares os mais diferentes da história. Em outras palavras: de Kant, já sabíamos que o "objeto" não poderia ser conhecido em si mesmo ("fim do realismo") e, a partir da Filosofia da História, descobrimos que não poderíamos mais afirmar a possibilidade de conhecer 
o "sujeito" ou de fundamentar as condições de possibilidade do conhecimento em um sujeito transcendental a-histórico ("fim do idealismo"). Para a negação do sujeito a-histórico, basta verificar que "causa" e "substância", conceitos a priori no sujeito segundo Kant, não são verificáveis entre muitos "sujeitos" que não fazem a experiência considerada "científica"; isto é, em outros lugares que não a Ciência, tais conceitos simplesmente não existem ou não parecem fazer qualquer sentido...

E se a verdade existe, e não está no "objeto" nem no "sujeito" do conhecimento e, por outro lado, existe somente como verdade histórica, perguntam então os pensadores: onde estão localizados os juízos que enunciam o conhecimento verdadeiro produzido pela experiência? Responderá Benjamin: a verdade está na linguagem e somente pode ser interpretada objetivamente a partir e por causa da linguagem. Mais especificamente: a necessidade e a universalidade das ideias (note o uso de ideias em contraposição a conceitos) são possíveis não pela universalidade e necessidade de um sujeito transcendental, mas pela universalidade e necessidade presentes na linguagem... Entretanto, ao contrário do que se poderia inferir daí, corroboramos: mesmo na linguagem, não são os silogismos de uma linguagem conceitual que garantem a universalidade e a necessidade do conhecimento, mas a própria coerência do discurso, de quem fala e do que se fala... E para Benjamin isto faz toda a diferença, pois tudo fala e tudo que fala expressa ontologicamente; as ideias são "eternas" (se referindo a Platão), mas eternas porque residem na linguagem ou naquilo que faz do homem um ser absolutamente histórico e, portanto, "eterno"... Para o filósofo, a linguagem mítica está inerentemente presente no conhecimento produzido pelas Religiões, Artes, Política e pela própria Filosofia.

Walter Benjamin pertence à geração de filósofos pós-nietzschianos que procuram superar o problema dialético subjacente aos pares Heráclito e Parmênides, Platão e Aristóteles, medievais e modernos, onde a primazia é dada quase que unilateralmente ao uso de conceitos e da linguagem conceitual (logos), considerada superior ao uso de mitos e da linguagem mítica (mythos) em grande parte da história do pensamento ocidental (Muricy, 1988). A diferença entre Benjamin e outros filósofos de sua geração, como Heidegger, é a de que, apesar de propor uma ontologia que procura romper tanto com a metafísica antiga (e medieval) quanto com a metafísica moderna, Benjamin não o faz se referindo novamente à investigação de conceitos que permitam conhecer e determinar pelo pensamento em que consistem 
as modalidades ônticas ${ }^{8}$, mas apontando para a necessidade do resgate, por pouco que seja possível, da transparência da "linguagem do paraíso", característica primeira de uma linguagem primordial que, Benjamin argumenta, persiste na linguagem em geral até os nossos dias... Neste sentido, o filósofo resgata o valor do mito na Filosofia; rompe com a metafísica antiga, sim, mas, ao contrário dos modernos, não simplesmente recalcando-a. Benjamin propõe uma Filosofia que, através da construção de ideias, procura elaborar, salvar ou resgatar experiências que, mesmo quando antigas, comunicam aquilo que permanece e que, por isso mesmo, são capazes do novo naquele que se apropria delas...

Em resumo, ao contrário de Kant, Benjamin afirma que a condição de possibilidade do conhecimento não reside na capacidade do sujeito transcendental em regular a experiência; ao contrário, uma experiência pode produzir conhecimento mesmo quando não representada através de conceitos. Na verdade, segundo Benjamin, não há necessidade de qualquer representação; a re-presentação só seria necessária se o algo a ser representado estivesse ausente e, como para Benjamin, no experienciado, ainda quando se verifica o inexprimível, o inefável, a linguagem está sempre presente... De todo modo, como garantir que o conhecimento derivado da experiência singular de um sujeito não deva ser considerado como meramente especulativo? Na Crítica da Razão Pura, Kant justificou que um conhecimento é verdadeiro quando este resulta de um juízo sintético a priori, ou como explicamos, quando nele se verifica absoluta independência de toda e qualquer experiência; já para Benjamin, a possibilidade de atribuir valor de verdade a um conhecimento não está no sujeito transcendental, mas tão somente na linguagem. Benjamin, neste sentido, é "mais empirista" do que Kant, para quem "todo conhecimento deriva da experiência", mas, que, por outro lado, só pode ser resultado de um juízo sintético a priori. Para Benjamin, uma nova ontologia, que supera a metafísica de antigos, medievais e modernos, deve fornecer uma interpretação objetiva da relação entre homem e mundo na história em vez de oferecer qualquer explicação apriorística da realidade.

\footnotetext{
${ }^{8}$ Referimo-nos à filosofia de Martin Heidegger desenvolvida nos primeiros anos de seu ensino, - isto é, antes da chamada "viravolta" -, na qual se localiza grande parte da obra Ser e Tempo (1927).
} 


\section{BIBLIOGRAFIA}

BENJAMIN, Walter. Sobre a linguagem em geral e sobre a linguagem humana. In: Sobre arte, técnica, linguagem e política. Lisboa: Ed. Relógio D’Água, 1992.

. Experiência e Pobreza. In: Obras escolhidas. Vol. 1. Magia e técnica, arte e política. São Paulo: Brasiliense, 1987, p. 114-119.

Origem do Drama Barroco Alemão. São Paulo: Brasiliense, 1984.

Reflexões sobre a criança, o brinquedo e a educação. Trad. Marcus

Mazzari. São Paulo: Duas Cidades, 2002.

Sobre el Programa de la Filosofía Futura. In: Sobre el Programa de la

Filosofía Futura y otros ensayos. Caracas: Monte Avila Editores, 1970.

. Charles Baudelaire: um lírico no auge do capitalismo. In: Obras

Escolhidas, v.3. São Paulo: Brasiliense, 1989.

KANT, Immanuel. Crítica da Razão Pura. São Paulo: Nova Cultural, 1996.

. Crítica da Faculdade do Juízo. Rio: Forense Universitária, 1995.

. Crítica da Razão Prática. São Paulo: Martins Fontes, 2003.

HUME, David. Tratado da Natureza Humana. São Paulo: Unesp, 2000.

PLATÃO. A República. São Paulo: Difusão Européia do Livro, 1965.

ARISTÓTELES. Tópicos. São Paulo: Os Pensadores, Abril Cultural, 1978.

DESCARTES, René. Discurso do Método. Brasília: Universidade de Brasília, 1989.

LEIBNIZ, Gottfried. Meditaciones sobre el Conocimiento, la Verdad y las Ideas. In: OLAZO, E. (Ed.). G. W. Leibniz. Buenos Aires: Editorial Charcas, 1982.

SPINOZA, Baruch. Tratado Teológico Político. São Paulo: Martins Fontes, 2003.

HEGEL, Georg W. Friedrich. Fenomenologia do Espírito. Petrópolis: Vozes, 2007.

GALILEI, Galileu. Diálogo sobre os dois máximos sistemas do mundo

ptolomaico copernicano. São Paulo: Discurso Editorial e Impressão Oficial, 2004.

NEWTON, Isaac. Algumas questões filosóficas. Rio de Janeiro: EdUERJ e Contraponto, 2002, pp.22-30.

EINSTEIN, Albert. Como vejo a ciência, a religião e o mundo. Lisboa: Relógio D’Agua Editores, 2005.

KOYRÈ, Alexandre. O Pensamento Moderno. In: Estudos de História do

Pensamento Científico. Rio de Janeiro: Forense Universitária, 1991, pp.15-21.

HALL, Alfred R. From Galileo to Newton. New York: Dover Publications, Inc., 1981.

LOBATO, Cidiane. Sobre a fundamentação da moral na obra de Kant. In:

Investigação Filosófica, v.2, n.1, artigo digital 3, jun. 2011.

NIETZSCHE, Friedrich. Assim falou Zaratustra: um livro para todos e para ninguém. Rio de Janeiro: Civilização Brasileira, 2003. 
ARENDT, Hannah. As Origens do Totalitarismo. Trad. Roberto Raposo. São Paulo: Companhia das Letras, 1989.

NOVAES, Adauto. A crise da razão. São Paulo: Companhia das Letras, 1996. JAPIASSU, Hilton Ferreira. A crise da razão e do saber objetivo: as ondas do irracional. Rio de Janeiro: Letras e Letras, 1986.

VEGA, Alfredo Pena; NASCIMENTO, Elimar Pinheiro do. O Pensar Complexo: Edgar Morin e a Crise da Modernidade. Rio de Janeiro: Garamond, 1999.

HARVEY, David. Condição Pós-Moderna. São Paulo: Loyola, 1996.

TOURAINE, A. Crítica da Modernidade. Petrópolis: Vozes, 1994.

GIDDENS, Alain. As Conseqüências da Modernidade. São Paulo: Unesp, 1991.

HEISENBERG, Werner. The Physical Principles of the Quantum Theory. Trad. C. Eckart e F.C. Hoyt. New York: Dover, 1949.

BOHR, Niels. In: The quantum postulate and the recent development of atomic theory, Atomic Theory and the Description of Nature. Cambridge: Press, 1961.

HEIDEGGER, Martin. A doutrina de Platão sobre a verdade. Disponível em: <http://www.cfh.ufsc.br/ wfil/verdade.htm> Acesso em: 12 mai. 2010.

A caminho da linguagem. Petrópolis: Vozes, 2003.

. O fim da filosofia e a tarefa do pensamento. Em: Os Pensadores. $4 a$ ed. Trad. Ernildo Stein. São Paulo: Nova Cultural, 1999.

WITTGENSTEIN, Ludwig. Investigações Filosóficas. Petrópolis: Vozes, 1994.

MURICY, Katia. A magia da linguagem: filosofia, linguagem e escrita em Benjamin. Revista Educação Especial: Biblioteca do Professor - Benjamin pensa a educação, São Paulo, p. 76-85, mar. 2008.

Relação entre o conceito de História de Walter Benjamin e a concepção de História em Nietzsche. In: III Encontro Nacional de Filosofia, 1988, Gramado. Anais da ANPOF: Gramado, 1988.

HEIDEGGER, Martin. Ser e tempo. Trad. Marcia Sá Cavalcante Schuback. Petrópolis: Vozes, 2002. 